Hauptursachen für diese Entwicklung sind die zunehmende Zerstörung und Belastung von Gewässern und Sumpfgebieten, vor allem kleinerer Tümpel und Feuchtgebiete. Hervorzuheben als Verminderungsursache ist dann die sich immer stärker ausbreitende Störung bisher unbeeinträchtigter Naturgebiete durch den Erholungsverkehr und Wassersport. Beim Ausbau der Erholung an Gewässern oder bei der Erschließung von Feuchtgebieten für den Tourismus sollte darauf geachtet werden, daß Ruhezonen für die 'Tierwelt erhalten bleiben.

4. Gerichtsurteil für Vogelschutzgebiet: Das Regierungspräsidium Südbaden lehnte eine Erweiterung einer Tennisplatz-Anlage in den Geltungsbereich des "Naturschutzgebiets Vogelfreistätte Mettnau am Bodensee" mit der Begründung ab, „dem öffentlichen Interesse an der ungeschmälerten Erhaltung des Schutzgebietes sei eindeutig der Vorrang einzuräumen " gegenüber dem öffentlichen Interesse an der Tennisplatz-Erweiterung. Ein Widerspruch des Unternehmers wurde abgewiesen, ebenso eine darauffolgende Klage. Das Verwaltungsgericht Freiburg schloß sich der Auffassung der Vogelwarte Radolfzell, der Deutschen Ornithologen-Gesellschaft und der Staatlichen Vogelschutzwarte Baden-Württemberg an und erkannte die Klage des Unternehmers als unbegründet.

Diesem Urteil kommt für die Erhaltung von Naturschutzgebieten grundsätzliche Bedeutung zu.

\title{
Deutsche Ornithologen-Gesellschaft: Beiratswahl
}

Auf der diesjährigen Jahresversammlung der Deutschen Ornithologen-Gesellschaft in Wien werden drei neue Beiratsmitglieder gewählt werden. Der Generalsekretär bittet um Vorschläge von Kandidaten für die Wahl der Beiratsmitglieder; die Vorschläge müssen gemäß der Satzung spätestens sechs Wochen vor der Mitgliederversammlung beim Generalsekretär eingegangen sein.

\section{Persönliches}

Udo BäHrmann, seit 1915 Mitglied der DO-G, wurde am 24.9.1974 von der HumboldtUniversität Berlin durch die Verleihung der Ehrendoktorwürde ausgezeichnet. Damit wird die Arbeit eines Ornithologen anerkannt, der dem Phänomen der morphologischen Differenzierung von Populationen durch ihre exakte Analyse näherzukommen trachtete. Die Arbeiten BäHRmanns befassen sich vornehmlich mit Fragen der Biometrie von Vogelpopulationen und Details der Mauser.

Seinen 85. Geburtstag feierte im März GeORg von BruchHaudsen, Söcking, seinen 75. im Januar Prof. Bernhard Rensch (Münster) und seinen 60. im Februar Dr. Hans-Edmund Wolters (Bonn).

Prof. Dr. Rolf Dircksen wurde am 20. April 1975 der Kulturpreis der Stadt Bielefeld verliehen. 